\title{
Editor's introduction to volume 4
}

The introduction to Volume 3 of Popular Music made a point of stressing the interconnections between 'production' and 'consumption'. These interconnections affect not only the structure and genesis of the musical product, through the relation of markets to producers, but also, at the other pole of the process, its social meaning: at its simplest, there is no audience without the work of music making (hence 'performers and audiences'). If this twin volume is to present 'the other side of the coin', it too must nevertheless penetrate, from its own vantage-point (here 'reception' or 'music use'), into the entire cycle constituted by the circulation of musical goods.

Adorno (among others) has incisively pointed out the destructive results for proper study of this process of a narrow concentration on 'effects' (see, e.g., Adorno 1972). Asking listeners about their responses to music, as a basis on its own for reception research - that is, without placing this in the context constituted by the music itself, its mode of production and distribution, and its moment of consumption, and without raising deeper questions about the nature of listening per $s e$ - is the mirror, theoretically, of positivistic representations of the organisation of production, or of formal 'musical facts', as in themselves defining the whole significance of popular music. But if 'effects' research of this simplistic kind, and analogous study of 'uses', is widely discredited, this merely helps to cement in place a conceptual split between the moment of consumption on the one hand and the sphere of the musical 'text' and its production on the other. We are still stuck over the relationship between the subjective responses of listeners and the structures of the musical product or performance and Adorno's 'critical thought from above' was ultimately no more successful here than any other approach. There is a tendency, it seems, for work to cohere around either cultural (especially subcultural) theory, with its liking for grand speculation and a contextual view of musical meaning, or a textual semiotics in which the audience appears, if at all, only as an abstraction. This problem is compounded by the particular openness of musical codes - who can guarantee particular responses, interpretations, uses? - and by the growing heterogeneity and fluidity of the popular music scene - the fixity of specific audience/style relationships seems increasingly open to doubt. 
Needless to say, this volume does not pretend to solve the problems, but all the articles included here do bear on it, either in large issues such as the nature of listening, of musical pleasure or of the relationship between musical form and class-specific meaning - or on particular aspects of discrete situations. In focus (text/listener, e.g.) and orientation (theoretical/empirical) they are inevitably disjunct: a grand coherence does not yet seem to be on the agenda.

We begin and end with pairs of articles on performer-audience relationships, the first pair (by Vic Gammon and Katherine Preston) situated in the nineteenth century, the second (by Umberto Fiori and Chris Cutler) focusing on the situation now and even in the future. If the first two represent aspects of a bygone world, and the second two point from today towards a possible tomorrow, the remaining articles inhabit the in-between period often inadequately known as that of mass culture - though several (notably Louis van Elderen's, Shuhei Hosokawa's and Lawrence Grossberg's) delineate elements of its possible demise. The first group here (by Carole Pegg, Judith Herd and Louis van Elderen) are concerned with the definition of audiences and their musical tastes; the determinants of these preferences, and their relationship to audience identity is a strong theme. The next group discuss aspects of listening itself, in what is taken to be its standard popular music mode (by Helmut Rösing) and in two more specifically contemporary contexts: that of live outdoor dissemination in urban settings (Paolo Prato) and that constituted by use of the 'walkman' (Shuhei Hosokawa). Rock music reception has traversed the boundaries of these and other modes of listening, during their evolution through the $1950 \mathrm{~s}-80 \mathrm{~s}$ period; and indeed rock is a component of the discussion in all the articles of Parts 2 and 3. But rock is so important, for many reasons, to the development of an adequate theory of popular music meaning that it merits separate treatment too. In Part 4, Brian Torode and Barbara Bradby, and then Sean Cubitt, examine - in different ways - the 'effects' of particular rock and roll texts, while Larry Grossberg develops a framework for understanding the social significance of the category as a whole. This brings us back to the final group of articles, in which the central question is how rock's significance can operate on a political level. Can we move from an Adornian concept of consumption - to the extent that it existed - or even from consumption per se, to musical responses, that is, active involvement: a collective self-production?

\section{Reference}

Adorno, T. W. 1972. 'Theses on the sociology of art', Working Papers in Cultural Studies, 2, pp. 121-8 